\title{
Effect of Clove Oil and Benzocaine on the Respiratory Metabolism of Angel Fish Pterophyllum scalare
}

\author{
Anulekshmi Chellapan ${ }^{1}$, C. B. T. Rajagopalsamy ${ }^{2 *}$ and G. Indra Jasmine ${ }^{2}$ \\ 'Central Marine Fisheries Research Institute, Mumbai; anulekshmi29@yahoo.co.in \\ 2Fisheries College and Research Institute, TANUVAS, Thoothukudi, India; lalithacbt@yahoo.com, \\ jasminearuldass@yahoo.com
}

\begin{abstract}
Anesthetics play an important role in fisheries research and aquaculture and are used to facilitate various handling procedures, such as weighing, sorting, collection of eggs and milt, tagging and medical treatment. Clove oil and benzocaine are approved anesthetic by US Food and Drug Administration. The present study investigates the effect of anesthetics on the respiratory metabolic parameters such as $\mathrm{O}_{2}$ consumption rate, $\mathrm{CO}_{2}$ output rate, $\mathrm{NH}_{3}-\mathrm{N}$ excretion rate, $\mathrm{RQ}, \mathrm{AQ}$ and opercular activity of Angel fish, Pterophyllum scalare. The concentration of clove oil and benzocaine were selected based on the time of induction of sedation and recovery of the Angel fish. The concentration of clove oil selected for the Angel fish were $5 \mathrm{ppm}, 15 \mathrm{ppm}, 30 \mathrm{ppm}, 45 \mathrm{ppm}, 55 \mathrm{ppm}$ and the benzocaine concentration were $30 \mathrm{ppm}, 45 \mathrm{ppm}, 50 \mathrm{ppm}, 100 \mathrm{ppm}$, $200 \mathrm{ppm}, 300 \mathrm{ppm}$ and $400 \mathrm{ppm}$. The minimum values of respiratory metabolic parameters in clove oil-anaesthetized Angel fish P.scalare were observed at the concentration of $45 \mathrm{ppm}$ while the same was in $50 \mathrm{ppm}$ in the case of benzocaine treatment. Simulated transportation experiments were conducted for Angel fish and the results suggested that 50ppm benzocaine was the optimum dose of anaesthetics for safe transport of Angel fish.
\end{abstract}

Keywords: Respiratory Metabolism, Angel Fish, Anesthetics, Clove Oil and Benzocaine.

\section{Introduction}

In aquaculture operations, anesthetics are very important because they minimize the stress in fishes and reduce physical injury during various handling practices like weighing, length-measuring, tagging, sampling etc. [4]. Anesthetics can help significantly in mitigating physiological stress, reducing metabolic rates, and thus reducing oxygen consumption, and ammonia and carbon dioxide excretion [23]. The use of anesthetics becomes essential in the transportation medium [22] and according to him, lowering the metabolic activities will result in a reduced rate of oxygen consumption, along with carbon dioxide, ammonia outputs and excretion of other wastes. Further, anesthetics control excitement and hyperactivity in fishes, reduce the chances of injury and this eases their handling
[7]. Clove oil is a highly-effective fish anesthetic with no side effects. The advantages are that it is locally available and inexpensive [25].

According to Osborn [16], the reduction in consumption of oxygen is caused by an anesthetic that seems to increase the ability of fish to withstand lower concentrations of dissolved oxygen. The gills decrease their functions under anesthesia due to the depression of opercular movements and associated nervous control of breathing [21]. Durve [5] stated that the metabolic rate in anesthetized fish was lowered by nearly half and thereby the weight of fish per unit volume of water could double during transportation. The present study is designed to understand the respiratory metabolism [oxygen $\left(\mathrm{O}_{2}\right)$ consumption, carbon dioxide $\left(\mathrm{CO}_{2}\right)$ output, Ammonia-Nitrogen $\left(\mathrm{NH}_{3}-\mathrm{N}\right)$ excretion, respiratory quotient (RQ), and ammonia quotient (AQ)] of

* Corresponding author:

C. B.T. Rajagopalsamy (lalithacbt@yahoo.com) 
the anaesthetized freshwater Angel fish Pterophyllum scalare.

\section{Materials and Methods}

\subsection{Clove Oil}

Clove oil is a pale yellow liquid distilled from theleaves, buds, and stems of the clove tree (Eugenia caryophyllus). Its active ingredients are eugenol [ $\alpha$-methoxy-4-2 (2-propenyl)Phenol] and iso-eugenol (4-propenyl-2-methoxy phenol), which can comprise $90-95 \%$ of clove oil by weight [5]. A stock solution of $10 \mathrm{ppt}$ was made by mixing $10 \mathrm{ml}$ of clove oil in one liter of boiled freshwater since the density of clove oil is approximately $1.0 \mathrm{~g} / \mathrm{ml}$, and by convention the concentration by weight was $10 \mathrm{~g} / 1$ [25]. Cloves, clove oil, and eugenol are all listed by the US Food and Drug Administration [26] as being safe for humans when used at levels not exceeding 1500 ppm [27].

\subsection{Benzocaine}

Benzocaine (ethyl-p-aminobenzoate) was selected as one of the best candidates among 16 anesthetics tested by Gilderhus and Marking [9]. It acted more rapidly in lower concentrations. Benzocaine was dissolved in pure ethanol at the rate of $1 \mathrm{~g} / 30 \mathrm{ml}$ to make a stock solution [10]. Aliquots of the stock solution were used to achieve the desired concentrations in test containers. Benzocaine is registered with the US Food and Drug Administration for use as an anesthetic in fish culture, management, and research [26].

\subsection{Experimental Fish}

Angel fish P.scalare was purchased in a healthy condition from a private aquarium. The length of the Angel fish P.scalare varied from $52 \mathrm{~mm}$ to $67 \mathrm{~mm}$ while the weight was between $1.23-1.67 \mathrm{~g}$. The angel fish were reared in the laboratory in FRP tanks each measuring 1 meter diameter and $40 \mathrm{~cm}$ height (circular cylindrical type). Freshwater up to the level of $30-35 \mathrm{~cm}$ was filled in all the tanks. Provision was made for aeration for 24 hours in a day in all the rearing tanks. Fifty percent of the water was changed once a week to maintain the water quality parameters at the optimum level. The commercial aquarium feed was fed to the Angel fish at the rate of 5 percent of the body weight and feeding was undertaken twice a day.

\subsection{Experimental Setup}

All the experiments were conducted in glass tanks with a capacity of 4 liters. Identical containers and conditions were used for the induction of sedation and recovery after anesthetization. Appropriate quantities of anesthetics were added to the experimental tank to conduct the experiments. The fish were anesthetized in the induction tank to get anesthetized and then replaced in the recovery tank. Well-aerated water was used for the recovery of the Angel fish. The oxygen and carbon dioxide and the $\mathrm{NH}_{3}-\mathrm{N}$ levels were measured in the experimental tank during the initial stage, and at durations of one hour and three hours of the experiment to study the various parameters of respiratory metabolism such as i) Oxygen consumption rate (OCR), ii) Carbon dioxide output rate (COR), iii) Ammonia-N excretion rate (AER), iv) Respiratory quotient (RQ), and v) Ammonia quotient (AQ). During simulated transportation experiments, the anesthetized fish were introduced to the transportation bag. The average weight of the Angel fishes was $1.39 \pm 0.24 \mathrm{~g}$. Initial levels of oxygen, carbon dioxide, and $\mathrm{NH}_{3}-\mathrm{N}$ were measured and the OCR, COR, and AER were estimated after 24 hours, 48 hours, and 72 hours of incubation of Angel fish.

\subsection{Experiment 1}

\subsubsection{Initial Anesthetization Experiment}

Laboratory grade clove oil and benzocaine were purchased from Hi-MEDIA. The range of concentration of clove oil and benzocaine used in the present study was selected after conducting the initial anesthetization tests from the minimum to the maximum levels in Angel fish. In the case of the Angel fish, the concentration of clove oil used for the initial anesthetization experiment ranged from $5 \mathrm{ppm}$ to 60 ppm ( 5 ppm, 10 ppm, 15 ppm, 20 ppm, 25 ppm, 30 ppm, 35 ppm, 40 ppm, 45 ppm, 50 ppm, 54 ppm, 55 ppm, 60 ppm) and the concentration of benzocaine used ranged from 30 ppm to $500 \mathrm{ppm}$ (30 ppm, $35 \mathrm{ppm}, 40 \mathrm{ppm}, 45 \mathrm{ppm}, 50$ ppm, 55 ppm, 60 ppm, 65 ppm, 70 ppm, 80 ppm, 90 ppm, 100 ppm, 125 ppm, 150 ppm, 175 ppm, 200 ppm, 215 ppm, $300 \mathrm{ppm}, 350 \mathrm{ppm}, 400 \mathrm{ppm}, 450 \mathrm{ppm}, 500 \mathrm{ppm})$. The induction time for the four stages of anesthetization and the recovery time were noted and recorded for all initial anesthetization experiments with Angel fish. From these initial experiments, the level of concentration of anesthetics at which the Angel fish attained sedation in the least 
induction time along with the highest recovery time was chosen as the maximum level of selected anesthetics for the present study. In the case of the Angel fish, $30 \mathrm{ppm}$ and 50 ppm were selected as the maximum levels of concentration of clove oil and benzocaine respectively. After selecting the minimum and maximum levels of concentration of selected anesthetics, the following concentrations of clove oil and benzocaine were selected to conduct the research experiments for assessing their effect on the respiratory metabolism of the Angel fish.

$\begin{aligned} & \text { Clove } \\ & \text { oil }\end{aligned}$
$\begin{aligned} & \text { Benzo } \\ & \text { caine }\end{aligned}$

The criteria used to select the concentration levels of the anesthetics were that the ideal anesthetic should permit 1) a reasonable duration of exposure to produce anesthesia within 3 minutes or less; 2) allow recovery within 5 minutes or less; 3 ) cause no toxicity to fish at the treatment levels; and 4) be reasonable in cost.

\subsection{Experiment 2}

\subsubsection{Estimation of Respiratory Metabolism}

The selected anesthetics were mixed with water in the experimental tank to achieve the desired concentration. Angel fish collected from the rearing tank were introduced into the experimental tank with a scoop net to avoid stress. The time of induction of anesthesia was noted and when the fish reached the surgical plane of anesthesia, they were then transferred to the recovery tank containing the wellaerated water [4]. The rearing tank was cover with glass lid without any air bubble and sealed with grease to avoid contact with external atmosphere. The opercular movement of the control fish was noted for every one minute with an interval of 15 minutes by visual observation during the entire period of experiment. The opercular movements of the anesthetized fishes were noted during and after the recovery period for every one minute with an interval of 15 minutes by visual observation during the entire period of experiment. The respiratory metabolic parameters such as OCR, COR, and AER were estimated within durations of 1 hour and 3 hours. The dissolved oxygen, free carbon dioxide and ammonia- $\mathrm{N}$ levels in the experimental tank water was estimated by adopting standard methods described by
AOAC [1]. The rate of oxygen consumption, carbon dioxide output, and $\mathrm{NH}_{3}-\mathrm{N}$ excretion was estimated using the following formula [14].

$$
\mathrm{OCR} / \mathrm{COR} / \mathrm{AER}=(\mathrm{I} \sim \mathrm{F}) \times \frac{\mathrm{V}}{1000} \times \frac{1000}{\mathrm{~g}} \times \frac{60}{\mathrm{t}}
$$

where $\mathrm{I}=$ Initial level; $\mathrm{F}=$ Final level; $\mathrm{V}=$ Volume of water in milliliter; $\mathrm{g}=$ Weight of the fish in grams; $\mathrm{t}=$ Experimental duration in minutes

The Respiratory quotient (RQ) and Ammonia quotient (AQ) were calculated by using the following formula [14]

$$
\begin{aligned}
& \mathrm{RQ}=\frac{\text { Volume of } \mathrm{CO}_{2} \text { output }}{\text { Volume of } \mathrm{O}_{2} \text { consumption }} \\
& \mathrm{AQ}=\frac{\text { Volume of } \mathrm{NH}_{3}-\mathrm{N} \text { excretion }}{\text { Volume of } \mathrm{O}_{2} \text { consumption }}
\end{aligned}
$$

\subsection{Experiment 3}

\subsubsection{Simulated Transportation Condition Experiment}

The angel fishes were starved for $24-48$ hours to empty their digestive tracts to reduce ammonia production during the transportation of fishes [3]. The optimum concentration of clove oil and benzocaine used for this simulated transportation condition was selected from the results of the research experiment 2 . The optimum concentration of clove oil and benzocaine was $45 \mathrm{ppm}$ and $50 \mathrm{ppm}$ for Angel fish. The anesthetized fishes in selected optimal concentrations were transferred into the polythene bags containing welloxygenated water and compressed oxygen in 1:3 ratio [13] and these oxygenated polythene bags were tied with rubber bands. The OCR, COR, AER, RQ, and AQ were estimated after 24 hours, 48 hours, and 72 hours.

The results of the present investigation were analyzed statistically using the ANOVA test and the levels of significance at $\mathrm{P}<0.05$ and $\mathrm{P}<0.01$ were considered for validation [24].

\section{Results}

\subsection{Effect of Anesthetics on Opercular Activity}

In clove oil anesthetization, the opercular beat showed a general decreasing trend from the beginning to the end of 
the experiment excepting in those Angel fishes treated in $45 \mathrm{ppm}$ and $55 \mathrm{ppm}$ of the concentration (Figure 1). The statistical analysis reveals that the opercular activities of the Angel fishes varied significantly $(\mathrm{P}<0.01)$ between the experimental duration and the treatments (Table 1.1). In all the concentrations of benzocaine, the opercular beat of

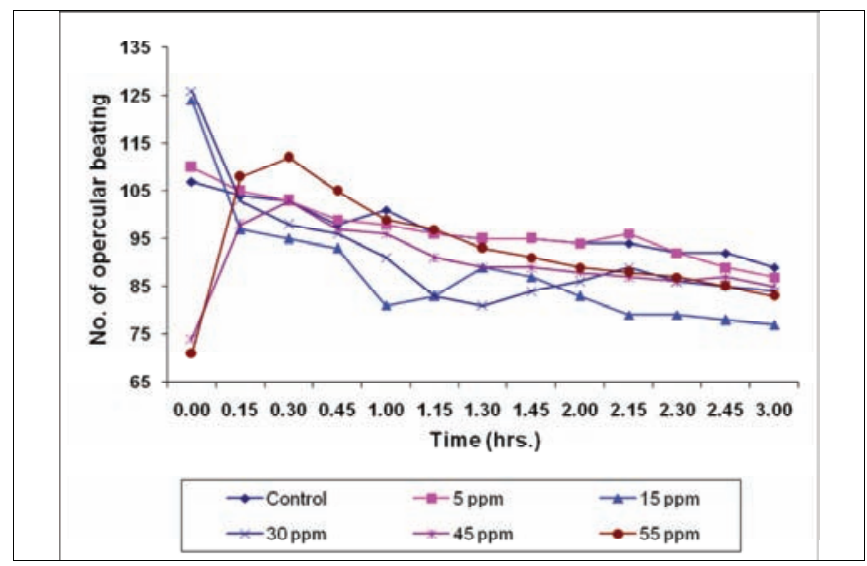

Figure 1. Effect of clove oil on the opercular beating of anaesthetized and control Angel fish Pterophyllum scalare.

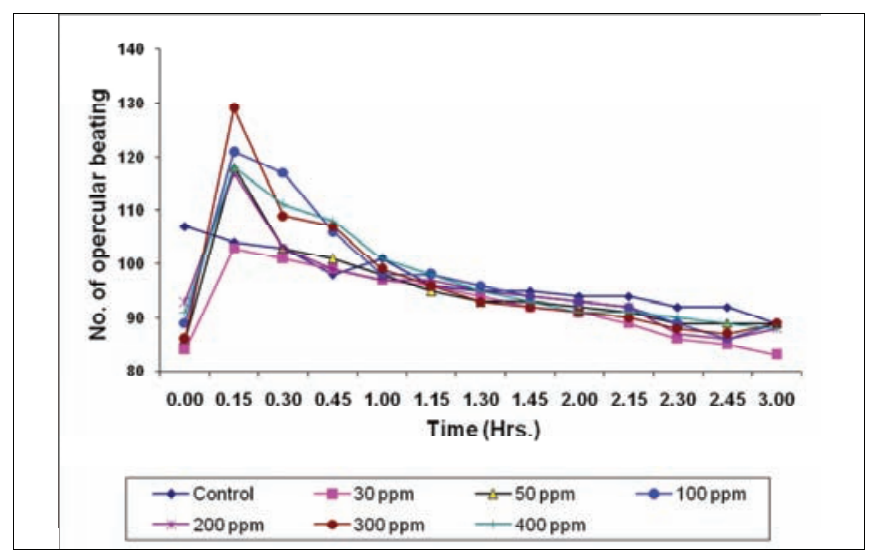

Figure 2. Effect of benzocaine on the opercular beating of anaesthetized and control Angel fish Pterophyllum scalare.

Table 1.1 Statistical significance of opercular activity of control and anaesthetized Angelfish Pterophyllum scalare

\begin{tabular}{llll}
\hline Clove oil & & Benzocaine & \\
\hline Time of incubation & $\mathrm{P}<0.01$ & Time of incubation & $\mathrm{P}<0.01$ \\
Treatments & $\mathrm{P}<0.01$ & Treatments & $\mathrm{P}<0.01$ \\
\hline
\end{tabular}

Angel fishes up to the first fifteen minute were less than that of the control fish (Figure 2). Afterwards, the opercular beating showed decreasing trends among the control and all the anesthetized fishes. During the first 15 minutes of experimental duration, the maximum number of opercular beating was observed in Angel fishes anesthetized in $300 \mathrm{ppm}$ of the concentration. The analysis of variance (ANOVA) shows that the activity showed significant difference $(\mathrm{P}<0.01)$ between time and treatment parameters (Table 1.1).

\subsection{Effect of Anesthetics on the Respiratory Metabolism}

The OCR (Oxygen consumption rate), COR (Carbon dioxide output rate), and AER (Ammonia-N excretion rate) of the Angel fish in controlled conditions showed highest value during the first and three hour test when values recorded in the clove oil anesthetized Angel fishes were compared (Figure 3 ). The RQ (Respiratory quotient) showed decreasing values from the one hour to the three hour test while the AQ (Ammonia quotient) showed increasing values from the one hour test to the three hour incubation in all the control and clove oil-treated Angel fishes. The lowest OCR and COR was observed in the $45 \mathrm{ppm}$ treatment (both one hour and three hour test) and the lowest AER was recorded in the $55 \mathrm{ppm}$ (one hour test) and the $45 \mathrm{ppm}$ treatment (three hour test). The statistical analysis revealed that all parameters except the $\mathrm{NH}_{3}-\mathrm{N}$ excretion rate, showed significant difference

Table 1.2 Statistical significance of parameters of respiratory metabolism of the control and clove oil anaesthetized Angel fish, Pterophyllum scalare

\begin{tabular}{lcc}
\hline Oxygen consumption rate & Clove oil & Benzocaine \\
\hline Time of incubation & $\mathrm{P}<0.01$ & $\mathrm{P}<0.01$ \\
Treatments & $\mathrm{P}<0.01$ & N.S. \\
$\mathrm{CO}_{2}$ output rate & & \\
Time of incubation & $\mathrm{P}<0.01$ & $\mathrm{P}<0.01$ \\
Treatments & $\mathrm{P}<0.01$ & N.S. \\
Respiratory Quotient & & \\
Time of incubation & $\mathrm{P}<0.001$ & $\mathrm{P}<0.01$ \\
Treatments & $\mathrm{P}<0.05$ & N.S. \\
Ammonia Quotient & & \\
Time of incubation & $\mathrm{P}<0.001$ & $\mathrm{P}<0.01$ \\
Treatments & $\mathrm{P}<0.05$ & N.S. \\
\hline
\end{tabular}




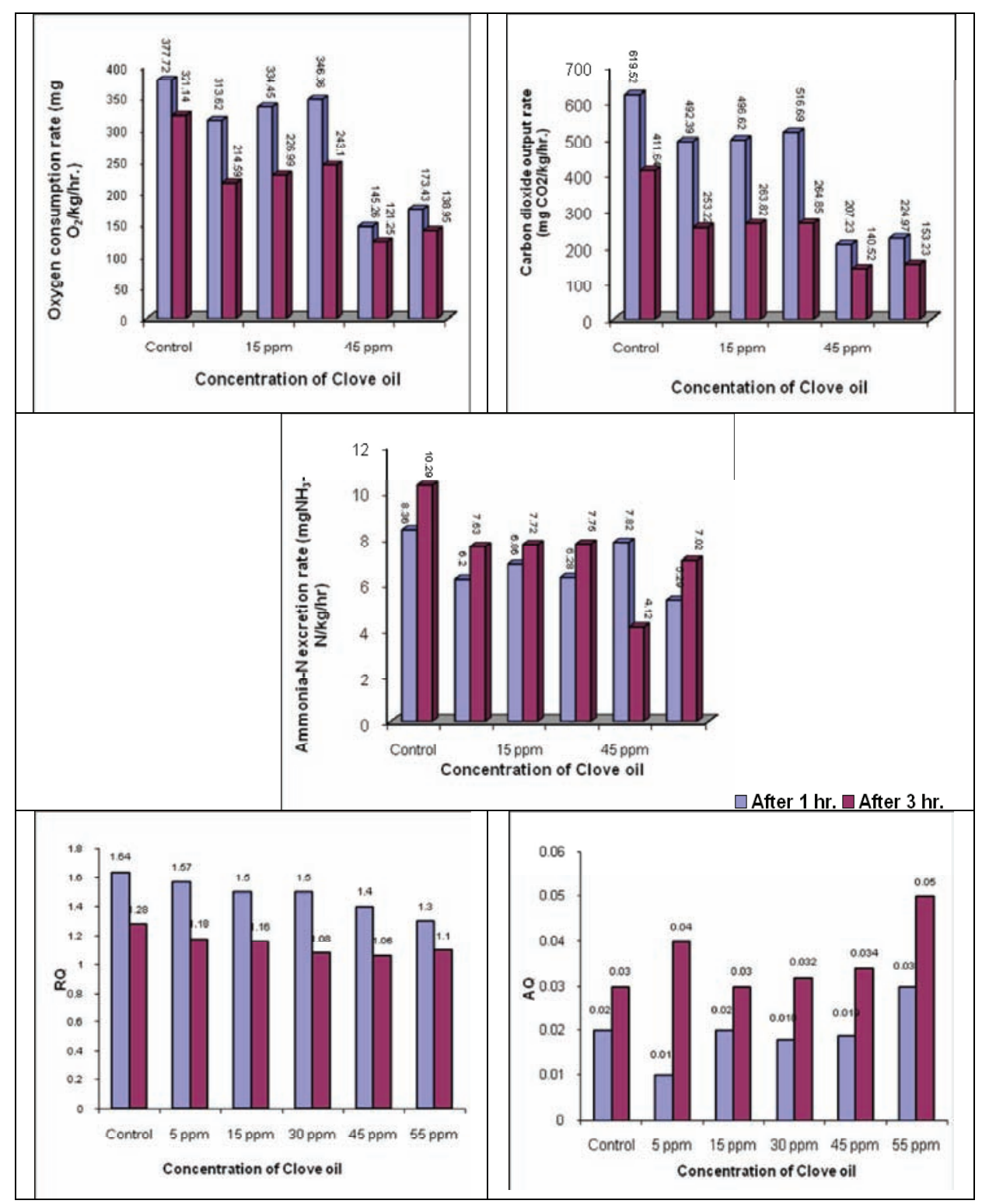

Figure 3. Effect of clove oil on the parameters of respiratory metabolism of anaesthetized and control Angel fish Pterophyllum scalare.

$(\mathrm{P}<0.05$ and $\mathrm{P}<0.01)$ between the time of incubation and treatments (Table 1.2). All the control and benzocaineanesthetized fishes showed decreasing values of OCR and COR in the one hour to the three hour experimental duration (Figure 4). The highest OCR was observed in the $200 \mathrm{ppm}$ treatment during the one hour test and the same was noticed in the three hour test during the $300 \mathrm{ppm}$ treatment. The lowest OCR was found in the $50 \mathrm{ppm}$ treatment during the three hour incubation. The COR showed the highest value during the $200 \mathrm{ppm}$ treatment while the lowest value was deduced among the $50 \mathrm{ppm}$ benzocaine-treated Angel fish. The highest
AER in the $200 \mathrm{ppm}$ treatment during the one hour test was $9.29 \pm 0.81 \mathrm{mg} \mathrm{NH}_{3}-\mathrm{N} / \mathrm{kg} / \mathrm{hr}$ and the lowest rate was found in the $50 \mathrm{ppm}(5.62 \pm 0.51 \mathrm{mg} \mathrm{NH}-\mathrm{N} / \mathrm{kg} / \mathrm{hr})$ treatment. The lowest value of RQ was obtained in the $50 \mathrm{ppm}$ test during both the one hour and three hour experiments. The lowest AQ value $(0.02 \pm 0.01)$ was obtained at $200 \mathrm{ppm}$ during the one hour incubation and the same was $0.03 \pm 0.01$ during the $300 \mathrm{ppm}$ treatment in the three hour incubation. Apart from the AER, all other parameters were significantly different only between the time of incubation at $\mathrm{P}<0.01$ level (Table.1.2). 


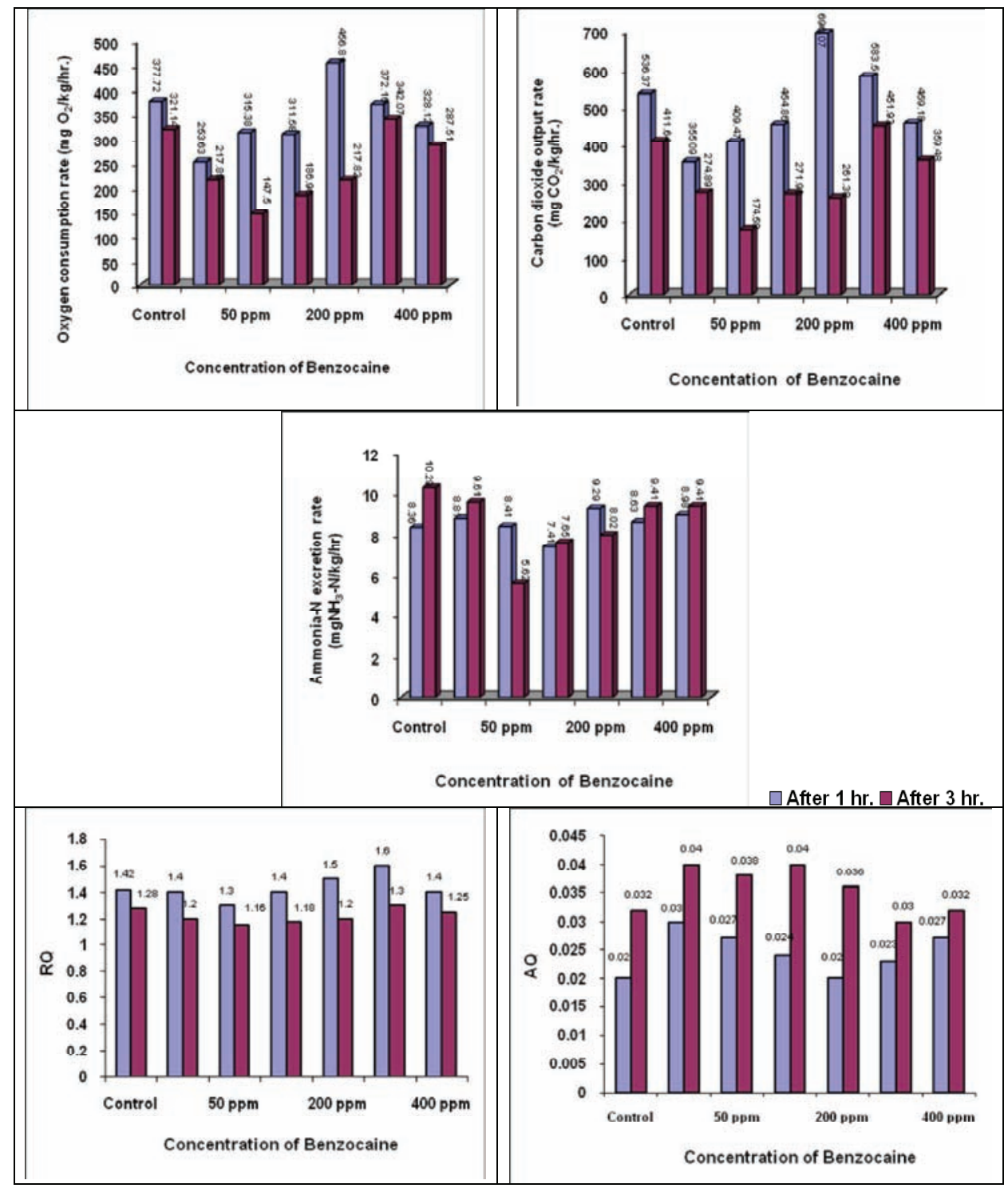

Figure 4. Effect of benzocaine on the parameters of respiratory metabolism of anaesthetized and control Angel fish Pterophyllum scalare.

\subsection{Effect of Anesthetics on Respiratory Metabolism During Stimulated Transportation Condition}

In case of clove oil and benzocaine-anesthetized Angel fish, the level of oxygen in the water decreased as the time of retention increased, whereas, the OCR showed higher values from 24 hours to 72 hours when compared with the control (Table 2). An increasing trend of $\mathrm{CO}_{2}$ levels was observed among the control and anesthetized Angel fishes and the highest value of the $\mathrm{CO}_{2}$ levels was seen in 72 hours of incubation among the control Angel fishes. In the case of COR and AER, it was a decreasing trend with an increase in the time of incubation and the lowest COR was observed under benzocaine-anesthetized conditions ( $51.59 \pm 1.82 \mathrm{mg} \mathrm{CO} /$ $\mathrm{kg} / \mathrm{hr}$ ) at 72 hours of retention. The level of $\mathrm{NH}_{3}-\mathrm{N}$ in water increased in the experiment regarding the control and anesthetized Angel fish as the time of retention increased. The highest level of ammonia- $\mathrm{N}$ was observed in controlled conditions whereas the lowest level of ammonia- $\mathrm{N}$ was recorded in thebenzocaine-anesthetized Angel fish at 72 hours of retention. The minimum value of RQ was found in benzocaine treatment during 72 hours of retention whereas the lowest AQ value was observed in clove oil and benzocaine-anesthetized Angel fish in 48 hours of incubation. The statistical analysis shows that oxygen and carbon dioxide levels showed 
significantly $(\mathrm{P}<0.05$ and $\mathrm{P}<0.01)$ different values between the time of incubation and treatment. But the $\mathrm{NH}_{3}-\mathrm{N} \mathrm{lev}$ els and the AER exhibited significantly $(\mathrm{P}<0.01$ and $\mathrm{P}<0.05)$ different values only within the incubation time (Table 1.3).

\section{Discussion}

In the present study, clove oil-anesthetized Angel fish showed the lowest opercular activity in 15 ppm concentration during the three hours of experimental duration. Pandit and Ghosh [19] stated that the difference in reduction of the opercular movement may be due to the short-term adaptation of fishes and this is true in the case

Table 1.3 Statistical significance of parameters of respiratory metabolism of control and anaesthetized Angel fish, Pterophyllum scalare in simulated transportation condition

\begin{tabular}{llll}
\hline Oxygen Level & \multicolumn{1}{c}{$\mathrm{CO}_{2}$ level } \\
\hline Time of incubation & $\mathrm{P}<0.01$ & Time of incubation & $\mathrm{P}<0.01$ \\
Treatments & $\mathrm{P}<0.05$ & Treatments & $\mathrm{P}<0.01$ \\
$\mathrm{NH}_{3}$-N level & & NH3-N excretion rate & \\
Time of incubation & $\mathrm{P}<0.05$ & Time of incubation & $\mathrm{P}<0.01$ \\
Treatments & $\mathrm{NS}$ & Treatments & $\mathrm{NS}$ \\
\hline
\end{tabular}

of clove oil-anesthetized Angel fish. Graham and Iwama [11] reported that Coho salmon and Rainbow trout recovered the pre-anesthesia values of ventilation rates within 1-2 hours with ketamine hydrochloride. Forgan and Forster [8] also recorded similar reductions in the ventilation frequencies of Blue Cod, Parapercis colias. Iwama [12] observed reduced ventilation rate in anesthetized Coho salmon, O. kisutch. However, in contrast, Dziaman et al. [6] recorded increasing trends of respiratory rhythm in higher concentrations of anesthetics (150 ppm) with C. carpio.

The OCR, COR, and RQ of clove oil-anesthetized Angel fish showed a decreasing trend for experiments of duration one hour to three hours in all the treatments and controls. The lowest value was observed in 45ppm clove oil-treated Angel fish. Similar observation was made by Beacker [2] that oxygen consumption and carbon dioxide output were the lowest in 45ppm clove oil-anesthetized Angel fish. However, the AQ value showed the least value in 5 ppm clove oil-anesthetized fishes. Beacker [2] reported that the anesthetized Angel fish did not show any variation in the ammonia-N excretion levels during different treatments with clove oil.

Benzocaine-anesthetized Angel fish showed the lowest values of OCR, COR, AER, and RQ when 50ppm-treated fishes were examined after a three hour incubation period. Pandit and Ghosh [19] observed a reduction of $40.94 \%$

Table 2. Respiratory metabolism of control and anaesthetized Angel fish Pterophyllum scalare in simulated transportation condition

\begin{tabular}{|c|c|c|c|c|c|c|c|c|}
\hline $\begin{array}{l}\text { Time of } \\
\text { incubation }\end{array}$ & $\begin{array}{l}\mathrm{O}_{2} \text { Level } \\
\left(\mathrm{mgO}_{2} / \mathrm{l}\right)\end{array}$ & $\begin{array}{c}\mathrm{O}_{2} \\
\text { consumption } \\
\text { rate } \\
\left(\mathrm{mgO}_{2} / \mathrm{kg} / \mathrm{hr}\right)\end{array}$ & $\begin{array}{l}\mathrm{CO}_{2} \text { Level } \\
\left(\mathrm{mgCO}_{2} / \mathrm{l}\right)\end{array}$ & $\begin{array}{c}\mathrm{CO}_{2} \text { output } \\
\text { rate } \\
\left(\mathrm{mgCO}_{2} / \mathrm{kg} / \mathrm{hr}\right)\end{array}$ & $\begin{array}{l}\mathrm{NH}_{3}-\mathrm{N}_{\text {Level }} \\
\left(\mu \mathrm{gNH}_{3}-\mathrm{N} / \mathrm{l}\right)\end{array}$ & $\begin{array}{c}\mathrm{NH}_{3}-\mathrm{N} \\
\text { excretion } \\
\text { rate } \\
\left(\mathrm{mgNH}_{3}-\mathrm{N} / \mathrm{kg} /\right. \\
\mathrm{hr})\end{array}$ & RQ & AQ \\
\hline \multicolumn{9}{|l|}{ Control } \\
\hline 24 hours & $6.58 \pm 0.7$ & $26.78 \pm 2.1$ & $2.29 \pm 0.8$ & $143.70 \pm 2.13$ & $0.19 \pm 0.03$ & $15.58 \pm 0.43$ & $5.3 \pm 0.1$ & $1.2 \pm 0.08$ \\
\hline 48 hours & $7.03 \pm 0.08$ & $66.95 \pm 1.8$ & $3.19 \pm 0.61$ & $125.74 \pm 1.33$ & $0.21 \pm 0.08$ & $8.51 \pm 0.21$ & $1.8 \pm 0.23$ & $0.13 \pm 0.07$ \\
\hline 72 hours & $7.45 \pm 0.23$ & $68.39 \pm 1.31$ & $3.29 \pm 0.73$ & $75.85 \pm 1.29$ & $0.36 \pm 0.05$ & $11.59 \pm 0.27$ & $2.4 \pm 0.91$ & $0.43 \pm 0.02$ \\
\hline \multicolumn{9}{|c|}{ Clove oil (45 ppm) } \\
\hline 24 hours & $8.82 \pm 0.21$ & $40.17 \pm 1.27$ & $1.89 \pm 0.72$ & $95.80 \pm 1.02$ & $0.17 \pm 0.03$ & $13.06 \pm 0.38$ & $2.3 \pm 0.82$ & $0.33 \pm 0.02$ \\
\hline 48 hours & $6.58 \pm 0.23$ & $93.73 \pm 1.59$ & $2.49 \pm 0.58$ & $83.78 \pm 1.89$ & $0.21 \pm 0.05$ & $8.75 \pm 0.43$ & $0.89 \pm 0.17$ & $0.1 \pm 0.01$ \\
\hline 72 hours & $5.36 \pm 0.31$ & $75.88 \pm 2.3$ & $2.79 \pm 0.53$ & $59.88 \pm 1.37$ & $0.28 \pm 0.07$ & $8.63 \pm 0.57$ & $0.91 \pm 0.23$ & $0.12 \pm 0.07$ \\
\hline \multicolumn{9}{|c|}{ Benzocaine (50 ppm) } \\
\hline 24 hours & $8.71 \pm 0.32$ & $53.57 \pm 1.3$ & $1.89 \pm 0.63$ & $95.80 \pm 1.25$ & $0.11 \pm 0.02$ & $12.70 \pm 0.51$ & $1.8 \pm 0.36$ & $0.24 \pm 0.03$ \\
\hline 48 hours & $6.25 \pm 0.22$ & $113.81 \pm 1.7$ & $2.29 \pm 0.49$ & $171.85 \pm 1.39$ & $0.21 \pm 0.06$ & $7.85 \pm 0.41$ & $0.63 \pm 0.38$ & $0.1 \pm 0.01$ \\
\hline 72 hours & $5.02 \pm 0.27$ & $89.27 \pm 1.9$ & $2.59 \pm 0.51$ & $51.89 \pm 1.82$ & $0.22 \pm 0.03$ & $5.87 \pm 0.34$ & $0.58 \pm 0.17$ & $0.12 \pm 0.01$ \\
\hline
\end{tabular}


oxygen consumption in benzocaine-anesthetized C. punctatus than the control fish. In the present investigation, in $50 \mathrm{ppm}$ concentration, the anesthetized Angel fish showed 45.93\% reduction in oxygen consumption when compared with the control experiment. A reduction of $75 \% \mathrm{O}_{2}$ consumption rate in the benzocaine-anesthetized $H$. fossilis during the three hours of incubation was recorded by Pandit and Ghosh [18]. The lowest value of AQ was assessed with 200 ppm benzocaine-anesthetized and control Angel fishes. Padmavathy et al. [17] reported that ammonia-N excretion rate was found to be positively correlated with oxygen consumption rate which indicated the relative utilization of protein under hypoxia.

During the simulated transport condition experiments, except for OCR, all the parameters such as COR, AER, $\mathrm{RQ}$, and AQ showed the lowest value in benzocaineanesthetized Angel fishes than the clove oil-treated and control fishes. Paterson et al. [20] stated that the increased carbon dioxide and ammonia levels were estimated during the air freighting of live Asian sea bass, Lates calcarifer. The statistical analysis reveals that oxyen and carbon dioxide levels showed significant $(\mathrm{P}<0.05 ; \mathrm{P}<0.01)$ difference among the time of incubation and treatments whereas the ammonia-N level and AER showed only significant difference at $\mathrm{P}<0.05$ and $\mathrm{P}<0.01$ level within the time of retention data. Mohanasundaram [15] observed the increase of oxygen consumption rate in Catla seeds and seeds of Etroplus suratenses during transportation. Ferreira et al. [7] reported that the $\mathrm{O}_{2}$ consumption, $\mathrm{CO}_{2}$ output, and $\mathrm{NH}_{3}-\mathrm{N}$ excretion showed reduced values in $25 \mathrm{ppm}$ anesthetized O. mossambicus than the control fishes. Pandit and Ghosh [19] opined that the anesthetics affected the brain either directly or through the blood which influenced the changes in behavior of fish as well as the metabolic parameters and they also stated that when the ornamental fishes were introduced into the anesthetic solution, they secreted abundant quantities of mucus which improved water blood barrier to reduce oxygen uptake. When the anesthetized fishes were put in freshwater for recovery, the secretion of mucus decreased and the fishes exhibited more oxygen consumption, and all these alterations were due to the metabolic changes occurring in the anesthetized Angel fish.

From the results of present experiment, it can be concluded that $45 \mathrm{ppm}$ clove oil and $50 \mathrm{ppm}$ of benzocaine seem to be the optimal concentration for the anesthetization of Angel fish P. scalare and further, the data derived from the simulated transportation condition experiment clearly indicates that benzocaine could serve as the best anesthetic in the optimum dose of $50 \mathrm{ppm}$ for the anesthetization of Angel fish, P. scalare during transportation.

\section{Acknowledgements}

The authors are thankful to the Dean, Fisheries College and Research Institute, Tamil Nadu Veterinary and Animal Sciences University, Thoothukudi 628008, Tamil Nadu, India, for rendering the facilities to conduct the present study. The first author gratefully acknowledges the Indian Council of Agricultural Research, New Delhi, India, for providing ICAR Junior Fellowship during the tenure of her M.F.Sc., post graduate study.

\section{References}

1. AOAC, Association of Official Analytical Chemists (1980). Official methods of analysis $13^{\text {th }}$ Edn., Washington, DC.

2. Beacker J J A (2006). Studies on the effect of anesthetic agents on live transport of ornamental cichlid fishes, M.F.Sc. Thesis, TANUVAS, 73.

3. Chatterjee J G, Chakraborthy L et al. (2007). Packing and transportation of ornamental fish, Fishing Chimes, vol 27(2), 41-42.

4. Cho G K, and Heath D D (2000). Comparison of tricaine methanesulphonate (M.S.22) and clove oil anesthesia affects on the physiology of juvenile Chinook salmon, Oncorhynchus tshawytscha (Walbaum), Aquaculture Research, vol 31(6), 537-546.

5. Durve V S (1975). Anesthetics in the transport of mullet seed, Aquaculture, vol 5(1), 53-63.

6. Dziaman R, Klyszejko B et al. (2005). The effect M.S.222 on the cardiac and respiratory function and behavior of common carp. Cyprinus carpio L. during general anesthesia, Acta Ichthyologica et Piscatoria, vol 35(2), 125-131.

7. Ferreira J T, Schoonbee H J et al. (1984). The use of benzocaine hydrochloride as an aid in the transport of Fish, Aquaculture, vol 42(2), 169-174.

8. Forgan L G, and Forster M E (2010). Oxygen consumption, ventilation frequency and cytochrome $c$ oxidase activity in blue cod (Parapercis colias) exposed to hydrogen sulphide or isoeugenol, Comparative Biochemistry and physiology Part C: Toxicology and Pharmacology, vol 151(1), 57-65.

9. Gilderhus P A, and Marking L L (1987). Comparative efficacy of 16 anesthetic chemicals on rainbow trout, North American Journal of Fisheries Management, vol 7(2), 288-292.

10. P A Gilderhus (1989). Efficacy of Benzocaine as an anesthetic salmonid fishes, North American Journal of Fisheries Management, vol 9(2), 150-153. 
11. Graham M S, and Iwama G K (1990). The physiologic effects of the anesthetic ketamine hydrochloride on two salmonid species, Aquaculture, vol 90(3-4), 323-331.

12. G K Iwama (1992). Anesthesia analgesia and euthanasia in fish, The care and use of Amphibians, Reptiles and Fish Research, Proceedings from a SCAW/LSUSVM-sponsored conference, Scientists Center for Animal Welfare, Maryland, 167-174.

13. Jameson J D, and Santhanam R (1996). Manual of ornamental fishes and farming technologies, Tamil Nadu Veterinary and Animal Sciences University, Chennai, 50-60.

14. Kutty MN (1981). Energy metabolism of mullets, Aquaculture of grey mullets, Ed. O.H. Oren, Cambridge University press, Cambridge and London, 219-264.

15. Mohanasundaram $P$ (1988). Role of oxygen and anesthetic in transportation of culturable fish and shellfish seeds, M.F.Sc. Thesis, TANUVAS.

16. Osborn P E (1951). Some experiments on the use of thiouracil as an acid in holding and transporting fish, Progressive Fish-Culturist, vol 13(2), 75-78.

17. Padmavathy P, Ramanathan N et al. (2002). Oxygen utilization in Cirrhinus mrigala and Labeo rohita under normoxic and hypoxic conditions, Indian Journal of Fisheries, vol 49(2), 115-121.

18. Pandit D N, and Ghosh T K (1999). Effect of an anaesthetic, benzocaine on the aquatic oxygen uptake in juveniles of facultative air-breathing fish, Heteropneustes fossilis (Bloch), Journal of Freshwater Biology, vol 12(3-4).
19. Pandit D N, and Ghosh T K (2005). Effect of Benzocaine on opercular movement and oxygen consumption in Channa punctatus (Bloch), Journal of the Indian Fisheries Association, vol 32, 149-155.

20. Paterson B D, Rimmer M A et al. (2003). Physiological responses of the Asian sea bass Lates calcarifer to water quality deterioration during simulated live transport: acidosis, red cell swelling, and levels of ions and ammonia in the plasma, Aquaculture, vol 218(1-4), 717-728.

21. Randall D J, and Hoar W S (1969). Special techniques, Anesthesia, Fish Physiology, Hoar W S, and Ramdall D J (Eds.), Academic Press, New York, vol 6, 511-523.

22. Sado E K (1985). Influence of the anesthetic quinaldine on some tilapias, Aquaculture, vol 46(1), 55-62.

23. Sandodden R, Finsted B et al. (2001). Transport stress in Atlantic salmon (Salmo salar L.), Aquaculture Research, vol 32(2), 87-90.

24. Snedecor G W, and Cochran W G (1967). Statistical methods, Oxford and IBH publishing Co., New Delhi, 593.

25. Soto C G, and Burhanuddin (1995). Clove oil as a fish anesthestic for measuring length and weight of rabbit fish (Siganus lineatus), Aquaculture, vol 136(1-2), 149-182.

26. USFDA (2006). United States Food and Drug Administration Information Bulletin, 3.

27. Walsh C T, and Pease B C (2002). The use of clove oil as an anesthetic for the long-finned Eel. Anguilla reinhardtri (Steindachner), Aquaculture Research, vol 33(8), 627-635. 